\title{
Isolation and Identification of a-Glucosidase Inhibitor From Aspergillus terreus F38
}

\author{
Siti Munasaroh ${ }^{1 *}$, Swasono R. Tamat $^{1}{ }^{1}$ Rizna Triana Dewi ${ }^{2}$
}

\begin{abstract}
1.Pharmacy Faculty, Pancasila University,Jl. Raya Lenteng Agung Timur No.56-80, Srengseng Sawah, Jagakarsa, Jakarta.

2. Research Center for Chemistry - Indonesian Institute of Sciences, Kawasan PUSPITEK, Serpong, Tangerang Selatan, Banten 15314.
\end{abstract}

Submitted: 09-05-2018

Revised: 02-06-2018

Accepted: $30-06-2018$

*Corresponding author Rizna Triana Dewi

Email:

riznatd@gmail.com

\section{INTRODUCTION}

The number of diabetes mellitus patient increases every year all around the world including Indonesia. The rising prevalence of diabetes has become a major problem worldwide, in 2015 it was estimated that there were 415 million people with diabetes aged 20 79 years was predicted to rise to 642 million by 2040. Three quarters $(75 \%)$ of those with diabetes were living in low- and middle income countries (Ogurtsova, et al., 2017). Noncommunicable diseases are estimated to account more than $50 \%$ of all deaths in Indonesia. Cardiovascular disease contributed to $30 \%$ of the total number of deaths followed by cancers $(13 \%)$, and diabetes (3\%) (Soewondo et al., 2013). The epidemiological and nutritional transitions have played a major role in these trends.

Postprandial hyperglycemia harbors an important role in DM type 2 progresses and specific complication such as diabetic neuropathy, retinopathy, and cardiovascular diseases (Shibano, et al., 2008).Therefore, controlled postprandial glucose level is an important strategy in preventing DM type 2 . Therapeutic approach can be done by delaying glucose absorption through inhibiting carbohydrate hydrolyzing enzyme such as $\alpha$ glucosidase within the digestive organs (Anurakkun, et al., 2007). Clinically used drugs nowadays consist of acarbose and miglitol which inhibits glycosidase such as $\alpha$-glucosidase and $\alpha$-amylase. However, several hypoglycemic agents have limitations such as side effects and increasing diabetes complication. Main side effects from $\alpha$-glucosidase inhibitor in gastrointestinal tract are bloating, nausea, and diarrhea. Natural $\alpha$-glucosidase inhibitor drug that comes from natural sources can be used as therapeutic approach to treat postprandial hyperglycemia for its assumed lower side effect and more affordable price compared to synthetic drugs (Sudha, et al., 2011).

Previous our study has shown that fungi of Aspergillus sp, can produce an $\alpha$-glucosidase inhibitors. Butyrolactone I, II, and three synthetic butyrolactone I derivatives were isolated from $A$. Terre us MC751 cultured in Czapek-dox broth, showed potential activity toward $\alpha$-glucosidase (Dewi, et al., 2014), sulochrin and its brominated derivated also produced by $A$. terreus RCC1 by solid state fermentation exhibition of significant activity 
against $\alpha$-glucosidase (Dewi, et al., 2018) and rubrofusarin showed potential activity inhibited of mamalian $\alpha$-glucosidase, which isolated from A. aculeatus cultured in potato dextrose broth (Dewi, et al., 2016). Continuing of our efforts to isolate potential a-glucosidase inhibitors from terestrial fungi, the objective of this study was to isolated active compound from $A$. terreus $\mathrm{F} 38$ which cultured in potato dextrose broth.

\section{MATERIAL AND METHODS}

\section{General Instrument and reagent}

UV-Vis absorption spectra of the active compound in methanol were recorded on a Agilent Techn. Carry 60 spectrophotometer. ESI-MS analysis was conducted by LCMS/ MS Xevo G2-XS QTOF (Waters). The nuclear magnetic resonanse (NMR) spectra were recorded at $500 \mathrm{MHz}$ for $1 \mathrm{H}$ and $125 \mathrm{MHz}$ for $13^{\circ} \mathrm{C}$ on a JEOL JNM-ECA 500 using Acetone- $d \sigma$ as solvent, with TMS as internal standard. The chemical shift values ( $\delta$ ) are given in parts per million (ppm), and coupling constant $(J)$ in $\mathrm{Hz}$.

Chromatography column was carried out using Merck Si-gel 60 and TLC analysis on precoated Si-gel plates (Merck Kieselgel 60 F254) and spots were detected under UV light. All solvents used were analytical grade and distilled prior to use.

$\alpha$-Glucosidase Type I: from yeast Saccharomyces cerevisiae (EC 3.2.1.20), bovine serum albumin and $p$-nitrophenyl- $\alpha-\mathrm{D}$ glucopyranoside ( $p$-NPG) as synthetic substrate of $\alpha$-glucosidase were purchased from Wako Pure Chemical Industries, Ltd(Osaka, Japan). Potato dextrose broth (PDB), peptone, malt extract, and Czapek-dox broth were purchased from DIFCO.

\section{Microorganisms and culture conditions}

Thefungal was obtained from the Indonesian Culture Collection of the Study Center for Biology - LIPI. The strains was prepared on potato dextrose agar plates and stored at $4^{\circ} \mathrm{C}$. The isolate was kept by monthly transfer onto PDA (Potato Dextrose Agar) and incubated at $30^{\circ} \mathrm{C}$ for 7 days in the dark.

Optimization of the culture medium was conducted by culturing the $A$. terreus $\mathrm{F} 38$ in three different media: PDB (250 g potatoes boiled in liquid for $1 \mathrm{~h}$, filtered and then added with water up to 1 Land $2 \%$ glucose.PMP (PDB medium added with $1.0 \%$ malt and $0.1 \%$ peptone) and Czapek-dox (CDB) (3\% sucrose, $0.2 \% \quad \mathrm{NaNO}_{3}, 0.1 \% \quad \mathrm{~K}_{2} \mathrm{HPO}_{4}$, $0.05 \quad \mathrm{MgSO}_{4} .7 \mathrm{H}_{2} \mathrm{O}, \quad 0.05 \% \quad \mathrm{KCl}, \quad 0.001 \%$ $\mathrm{FeSO}_{4} .7 \mathrm{H}_{2} \mathrm{O}$ ) incubated for 10 days in room temperature at static condition. After incubation day was over, mycelium and broth were separated and each was extracted by ethyl acetate (EtOAc), before then dried by rotary evaporator. The culture broth was prepared by 3 rounds of extraction for each broth $(500 \mathrm{~mL})$ with EtOAc $(2 \times 200 \mathrm{~mL})$. The dried extract obtained was assessed for $\alpha$-glucosidase inhibitory activity.

\section{Fermentation, extraction, and isolation}

To isolate the active compound, fermentation was carried out to obtain a total volume of $30 \mathrm{~L}$ PDB culture broth of $A$. terreus F38. The medium is incubated for 10 days in room temperature at static condition. After incubation, mycelium and broth were separated and each was extracted with $5 \times 1000 \mathrm{~mL}$ EtOAc. The crude extract was purified by column chromatograph using silica gel G60 (70-230 mesh) using a stepwise gradient $n$-hexane: EtOAc, to EtOAc: $\mathrm{MeOH}$ to obtain seven fractions (F1- F7). Fraction 5(F5) further sephadex chromatographed using $\mathrm{CHCl}_{3}$ : $\mathrm{MeOH}(1: 1)$ as system solvent to give fourteen fractions (F5.1-F5.14). Compound I (8.9mg) was obtained from purification from subfraction F5.8. The pure compounds were identified by instrumental analysis.

Compound I: as a yellowish gum. UV spectra $(\mathrm{MeOH}) \lambda_{\max } 304$, LCESI-MS $[\mathrm{M}+\mathrm{H}]^{+}$ $\mathrm{m} / \mathrm{z}$ 441.2843, calcd for $\left.\mathrm{C}_{24} \mathrm{H}_{24} \mathrm{O}_{8}\right]$. FTIR (KBr) Vmax 3334, 3086, 2937, 1741, 1093 $\mathrm{cm}^{-1}$. (Table III).

\section{Activity test of a-glucosidase inhibitor}

$\alpha$-Glucosidase inhibitory activity was evaluated according to the previously reported method (Dewi et al., 2014). Briefly, 250 $\mu \mathrm{L} \alpha-$ Glucosidase, $495 \mu \mathrm{L}$ of $0.1 \mathrm{M}$ phosphate buffer $(\mathrm{pH} 7.0)$, and $5 \mu \mathrm{L}$ of various concentrations of samples in DMSO $(50-200 \mu \mathrm{g} / \mathrm{mL})$ were pre-incubated at $37^{\circ} \mathrm{C}$ for $5 \mathrm{~min}$. The reaction was initiated by the addition of $250 \mu \mathrm{L}$ of $5 \mathrm{mM}$ - -NPG (Wako, Osaka, Japan). 
Table I. $\alpha$-Glucosidase inhibitory activity from three different culture broths of $A$. terreus F38

\begin{tabular}{ccccc}
\hline No & Media & Extract & Extract dried weight $(\mathbf{m g} / \mathbf{1 0 0} \mathbf{~ m L})$ & $\mathbf{I C}_{\mathbf{5 0}}(\boldsymbol{\mu g} / \mathbf{m L})$ \\
\hline 1. & PDB & M & 34 & 9.65 \\
& & F & 17 & 19.89 \\
2. & PMP & M & 55 & 13.34 \\
& & F & 19 & 77.18 \\
3. & CDB & M & 26 & 13.33 \\
& & F & 11 & 47.89 \\
\hline
\end{tabular}

Annotation: $\mathrm{M}=$ mycelium $; \mathrm{F}=$ filtrate

Table II. $\alpha$-Glucosidase inhibitory activity of Fractions 1-7

\begin{tabular}{cccc}
\hline No & Fraction & Fraction weight $(\mathbf{g})$ & $\mathbf{I C}_{50}(\boldsymbol{\mu g} / \mathbf{m L})$ \\
\hline 1. & F1 & 2.905 & $>1000$ \\
2. & F2 & 0.600 & $>1000$ \\
3. & F3 & 0.150 & 426.12 \\
4. & F4 & 5.8 & 263.41 \\
5. & F5 & 1.970 & 1.48 \\
6. & F6 & 0.018 & 202.64 \\
7. & F7 & 0.800 & 6.23 \\
\hline
\end{tabular}

The reaction was continued for $15 \mathrm{~min}$ leter at same condition and stopped by adding $1 \mathrm{~mL}$ of $0.1 \mathrm{M} \quad \mathrm{Na}_{2} \mathrm{CO}_{3} . \quad \alpha$-Glucosidase activity was determined by measuring the release of $p$-NPG at $400 \mathrm{~nm}$. Individual blanks for test samples were prepared to correct background absorbance where the enzyme was replaced with $250 \mu \mathrm{L}$ of phosphate buffer. \% Inhibition $=(\mathrm{A}-\mathrm{B}) / \mathrm{A} 9100$, where $\mathrm{A}$ was the absorbance of the control reaction and $\mathrm{B}$ was the absorbance in the presence of the sample $\mathrm{IC}_{50}$ is calculated by using linier regression equation with sample concentration as $\mathrm{x}$ axis and inhibition $\%$ as y axis.

\section{RESULT AND DISCUSSION}

In order to enhanced production of active compound, we initialy evaluated $\alpha$ glucose inhibitory activity of three differences EtOAC extract of $A$. terreus $\mathrm{F} 38$ which cultured in PDB, PMP, and Czapek-dox broth (Table I).

The result showed that mycelium extract and filtrate extract from PDB has the highest activity than others, with $\mathrm{IC}_{50}$ value of 9.65 and $19.89 \mu \mathrm{g} / \mathrm{ml}$, respectively. Furthermore, this result showed that intracellular metabolite of A. terreus $\mathrm{F} 38$ in PDB medium produce highest $\alpha$-glucosidase inhibitory activity. The addition of nitrogen source (PMP) or ion source (CDB) did not influence on $\alpha$-glucosidase inhibitory activity compared to PDB medium. Based on that reason, PDB medium is chosen to be used in further study.

On the next step of the study, fermentation was done with $30 \mathrm{~L}$ scale medium to obtain mycelium extract $\pm 13.0 \mathrm{~g}$ and $8 \mathrm{~g}$ of filtrate extract. The separation of mycelium EtOAc extract $( \pm 12.5 \mathrm{~g})$ was conducted by vacuum column chromatography with gradual polarity increase to obtain 7 fractions depending on TLC profile. Each fraction obtained was tested against $\alpha$-glucosidase (Table II).

Based on the test ( Table II), the fraction five (F5) and fraction seven (F7) showed strong activity against $\alpha$-glucosidase with $\mathrm{IC}_{50}$ value of 1.48 and $6.23 \mu \mathrm{g} / \mathrm{mL}$, respectively. F5 showed not only the highest inhibitory activity compared to other fractions, but also has relatively high yield $(1.97 \mathrm{~g})$ which allows further separation and purification. Fraction five (F5) was further purification through column chromatography with silica gel G60, sephadex LH60, and recristalization to obtain in the shape of yellow gum compound $\mathbf{I}$ (8.9mg). 
Table III. Comparison of ${ }^{13} \mathrm{C}$ and ${ }^{1} \mathrm{H}$ data of Butyrolactone I and Butyrolactone III $(400 \mathrm{MHz}$, in $\mathrm{CDCl}_{3}$ (Cazar, et al., 2005) to compound $\mathbf{I}(500 \mathrm{MHz}$, in Acetone- $d \sigma)$

\begin{tabular}{|c|c|c|c|c|c|c|}
\hline & \multicolumn{2}{|c|}{ Butyrolactone I* } & \multicolumn{2}{|c|}{ Butyrolactone III* } & \multicolumn{2}{|c|}{ Compound I** } \\
\hline & ${ }^{13} \mathrm{C}$ & ${ }^{1} \mathbf{H}$ & ${ }^{13} \mathrm{C}$ & ${ }^{1} \mathbf{H}$ & ${ }^{13} \mathrm{C}$ & ${ }^{1} \mathbf{H}$ \\
\hline 1 & 169.55 & - & 168.13 & - & 169.00 & - \\
\hline 2 & 137.37 & - & 138.34 & - & 140.0 & - \\
\hline 3 & 128.51 & - & 127.75 & - & 121.0 & - \\
\hline 4 & 86.21 & - & 84.94 & - & 86.00 & - \\
\hline 5 & 169.91 & - & 169.96 & - & 170.89 & - \\
\hline 6 & 38.67 & 3.58 & 38.24 & 3.53 & 39.25 & 3.45 \\
\hline & & 3.52 & & 3.48 & & 3.45 \\
\hline 1 ' & 122.06 & - & 121.23 & - & 124.30 & - \\
\hline $2^{\prime}$ & 129.16 & 7.65 & 129.02 & 7.62 & 130.03 & 7.61 \\
\hline 3' & 116.09 & 7.65 & 116.07 & 6.91 & 116.59 & 6.97 \\
\hline 4' & 156.98 & - & 158.12 & - & 158.85 & - \\
\hline 5 ' & 129.16 & 6.90 & 129.00 & 6.90 & 130.20 & 6.97 \\
\hline 6 & 116.09 & 7.65 & 116.07 & 7.62 & 116.07 & 7.61 \\
\hline $1 "$ & 124.60 & - & 123.43 & - & 124.90 & - \\
\hline 2" & 131.85 & 6.51 & 131.35 & 6.5 & 130.17 & 6.45 \\
\hline $3 "$ & 126.82 & - & 124.82 & - & 122.78 & - \\
\hline 4" & 153.16 & - & 156.45 & - & 153.16 & - \\
\hline $5 "$ & 115.12 & 6.52 & 114.83 & 6.50 & 116.59 & 6.47 \\
\hline 6" & 129.61 & 6.58 & 131.35 & 6.57 & 130.17 & 6.53 \\
\hline 7" & 28.86 & 3.12 & 26.63 & 2.37 & 26.20 & 2.54 \\
\hline 8" & 121.63 & 5.08 & 65.44 & 2.41 & 69.78 & 2.76 \\
\hline 9" & 134.10 & - & 58.32 & - & 59.78 & - \\
\hline $10 "$ & 25.68 & 1.65 & 23.31 & 1.24 & 20.25 & 1.14 \\
\hline $11 "$ & 17.17 & 1.70 & 23.31 & 1.25 & 20.25 & 1.28 \\
\hline 5-OMe & 53.60 & 3.80 & 53.52 & 3.78 & 53.82 & 3.79 \\
\hline
\end{tabular}

The ${ }^{1} \mathrm{H}$ and ${ }^{13} \mathrm{C}$ NMR spectra of compound I has similar patern with butyrolactone I, its major compound from A. terreus (Cazar, et al., 2005 and Dewi, et al., 2014). The ${ }^{1} \mathrm{H}$ NMR spectrum revealed two methyl singlets at $\delta_{\mathrm{H}} 1.14$ and 1.28 , presence of methoxy group $(-\mathrm{OC} \underline{\mathrm{H} 3})$ at $\delta_{\mathrm{H}} 3.79$. Three aromatic proton signal at $\delta_{\mathrm{H}} 6.53,6.47$, and 6.45, being for 1,2,4-trisubtituted phenol along with two doublets at $\delta_{\mathrm{H}} 7.61$ and 6.98 representing 1,4-disubtituted phenolic moity.

Supported by the signals at $\delta_{\mathrm{C}}$ three methine Signals at $\delta_{\mathrm{C}} 132.4,128.3$, and 115.1 for 1,2,4-trisubtituted benzene ring and 130.2 and 116.7 for 1,4-disubtituted phenolic, respectively. The ${ }^{13} \mathrm{C}$ NMR also showed the presence of two ester carbonyls at $\delta_{C} 170.89$ and 169.00. The significant difference observed in the NMR spectra between butyrolactone I and compound I was appeared high field shift of the $\mathrm{C} 8$ and $\mathrm{C} 9$ carbon signal at 59.78 and 69. $78 \mathrm{ppm}$ from olefin carbon signals of butyrolactone $\mathrm{I}$ at $\delta_{\mathrm{C}} 132.5$ and $123.4 \mathrm{ppm}$. Indicating presence of an oxygeneted carbon (epoxy group). From LCMS-MS, compound I has $(\mathrm{m} / \mathrm{z}) 441(\mathrm{M}+\mathrm{H})^{+}$indicates the molecular weight of the compound corresponds to molecular formula $\mathrm{C}_{24} \mathrm{H}_{24} \mathrm{O}_{8}$, which means has one more oxygent atom than butyrolactone I. This result supported presence of epoxy group.

Based on the NMR data, supported by ESI-MS data and reference (Table III), 
compound I was fully consistent with butyrolactone III (Figure 1). Butyrolactone III is reported as the synthetic epoxidation result of butyrolactone I with m-chloroperbenzoic acid (Rao, et al., 2000; Cazar, et al., 2005). Butyrolactone $\mathrm{I}$ is the main compound or metabolite produced by $A$. terreus, while butyrolactone III has never been reported as direct isolation product from $A$. terreus F38 extract. The biological activity of butyrolactone III that has been reported is cytotoxic activity against MCF7 cell (Rao, et al., 2000), and phytotoxic against Lactuca sativa and Panicum millaceum with $\mathrm{IC}_{50}$ value being $5 \times 10^{-4} \mathrm{M}$ and $5 \times 10^{-4} \mathrm{M}$ respectively, while the comparison compound acetochlor has $\mathrm{IC}_{50}$ value of 1 x10-5 M ( Cazar, et al., 2005). Activity of this compound as $\alpha$-glucosidase enzyme inhibitor has never been reported.

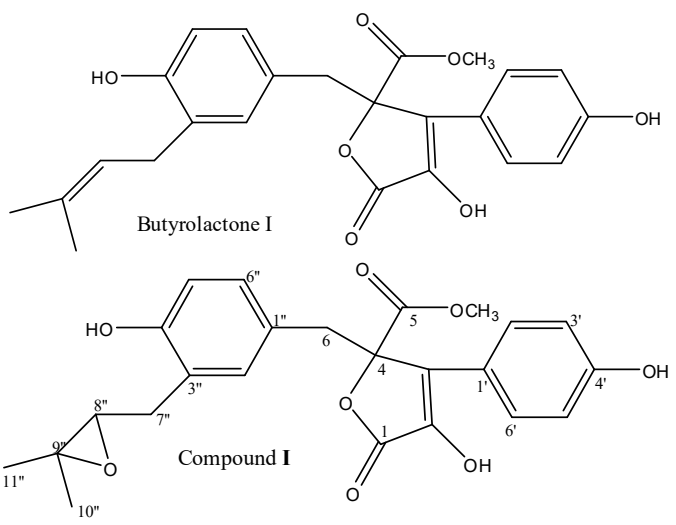

Figure 1. Chemichal structure of butyrolactone I and compound I (butyrolactone III)

\section{CONCLUSION}

A. terreus F38 cultured in potato dextrose broth (PDB) ethyl acetate extract showed the highest $\alpha$-glucosidase inhibitory activity compared to extract obtained from potato malt peptone (PMP) and Czaptek-dox broth (CDB). Butyrolactone III was isolated from $A$. terreus F38 as active compound against $\alpha$-glucosidase with $\mathrm{IC}_{50}$ value of $13,87 \mu \mathrm{g} / \mathrm{mL}$. Therefore, the metabolites from $A$. terreus $\mathrm{F} 38$ can be used as lead compound to design potent $\alpha$-glucosidase inhibitory agents.

\section{ACKNOWLEDGEMENTS}

This work was supported by the Program"Kegiatan Unggulan LIPI- Sub
Ketahanan Pangan dan Obat (1139/F/2015) from Indonesian Institute of Sciences (LIPI). The author also thanks to Mrs. Andini Sundowo, M.Si for the mass spectra measurement, Dr.Akhmad Darmawan and Dr. Sofa Fajriah for valuable discussion.

\section{REFERENCES}

Anurakkun N.J, Bhandari M.R, and Kawabata J. 2007. $\alpha$-Glukosidase inhibitors from devil tree (Alstonia scholaris). Chemistry. 103: 1319-1323.

Cazar M.E, Hirschmann G.S, and Astudillo L. 2005. Antimicrobial butyrolactone I derivatives from the Ecuadorian soil fungus Aspergillus terreus Thorn. var terreus, Word J. Microbiol. \& Biotech. 21: $1067-1075$.

Dewi R.T, Tachibana S, and Darmawan A. 2014. Effect on $\alpha$-glucosidase inhibition and antioxidant activities of butyrolactone derivatives from Aspergillus terreus MC751. Medicinal Chemistry Research. 23(1): 454-460.

Dewi R.T, Suparman A, Mulyani H, Darmawan A, and Lotulung PDN. 2016. Identification of a new compound as $\alpha$ glucosidase inhibitor from Aspergillus aculeatus. Annales Bogorienses. 20 (1):1822.

Dewi R.T, Darmawan A, Mulyani H, Lotulung P.D.N, Minarti and Megawati. 2018. $\alpha-$ Glucosidase inhibitory effect of sulochrin from Aspergillus terreus and its brominated derivatives. Malaysia Journal of Science 2018; 37 (1): 70 81.

Ogurtsova K, Fernandes J.D. da Rocha, Huang Y, Linnenkamp U, Guariguata L, Cho N.H, Cavan D ,Shaw J.E, and Makaroff L.E. 2017. IDF Diabetes Atlas: Global estimates for the prevalence of diabetes for 2015 and 2040. Diabetes Research and Clinical Practice. 128: 4050.

Rao K.V, Sadhukhan A.K, Veerender M, Mohan E.V.S, Dhanvantri SD, Sitaramkumar S, Babu MJ, Vyas K, and Reddy O.G. 2000. Butyrolactones from Aspergillus terreus, Chemical Pharmacy Bulletin. (Tokyo). 48(4): 559-562. 
Shibano M, Kakutani K, Taniguchi M, Yasuda M, and Baba K. 2008. Antioxidant constituens in the dayflower (Commeliana communis L.) and their $\alpha$ glucosidase-inhibitory activity. J. Natural Medecine. 62: 349-353

Soewondo P, Ferrario A, and Tahapary DL. 2013.Challenges in diabetes management in Indonesia: a literature review. Globalization and Health. 9:63.

Sudha P, Zinjarde S.S, Bhargava S.Y and Kumar A.R. 2011. Potent $\alpha$-amylase Inhibotory activity of Indian Ayurvedic Medicinal Plants. BMC Complementary and Alternative Medicine. 11: 5 